\title{
An Exploratory Study of the Influence of Severe Weather Radar Broadcasts
}

\author{
KATHLEEN SHERMAN-MORRIS and AMANDA M. LEA \\ Mississippi State University, Mississippi State, Mississippi
}

(Manuscript received 16 March 2015; review completed 6 June 2016)

\begin{abstract}
The local television weathercaster is an essential communicator of severe weather information to the public, but the impact of the particular aspects of his or her severe weather broadcasts has received little scholarly attention. To fill this gap, the current study examines the influence of two severe weather broadcasts where the weathercaster was located either on or off the screen. Specifically, we examine risk perception, recall, and intent to take protective action from a tornado. Our results indicate that the presence of the weathercaster on-screen did not lead to significant differences in risk perception, behavioral intent, or recall-with the exception of the intent to call someone in the tornado's path to alert them. In this one instance, respondents who viewed a reflectivity video without the weathercaster on screen were more likely to call someone living in a specific location in the video. The video that illustrates risk with a velocity image led to lower overall perceived risk, and less likelihood to take shelter. The differences are most likely related to differences in the spoken message rather than visual differences between the two radar types. This is supported by other differences in risk perception for locations within each video, where locations in the spoken message were rated higher in terms of risk perception and likelihood to take action than locations not mentioned verbally, even when the location verbalized was not labeled on the map.
\end{abstract}

\section{Introduction}

Television has been historically the most common source of both routine (Tan 1976; Lazo et al. 2009) and severe weather (Legates and Biddle 1999; Balluz et al. 2000; Brown et al. 2002; Hammer and Schmidlin 2002; Sherman-Morris 2005, 2010; Schmidlin et al. 2009) information; and the primary communicator of the weather information on television is the local weathercaster (Wilson 2008). Despite this importance, few studies (e.g., Sherman-Morris et al. 2005; Drost et al. 2015) have examined the influence that the weathercaster has on factors such as trust in severe weather information, risk perception, behavior, or recall of information.

During the span of severe weather coverage weathercasters must simultaneously play many roles. This includes: passing on damage reports from storm spotters, emergency managers, and the public; monitoring and communicating with multiple audiences via social media; and communicating warnings issued by the National Weather Service. A weathercaster will often communicate the situation live (on-air) from the first tornado warning issued until the last warning expires. Explanation of radar images takes a significant portion of this on-air time, although we know little about what viewers know or take away from watching the radar explanation. Broadcasters tend to use body language to help viewers understand what the images mean (Cassell et al. 1998; Beattie and Shovelton 1999; Wilson 2008; Drost et al. 2015). For example, the location of a storm and areas likely to be affected by the most dangerous portion of the storminterpreted from reflectivity radar products - can be easily communicated to viewers by hand gestures. Likewise, rotation of a storm interpreted from velocity radar products can be explained using hand motions to indicate the possibility of a tornado and the most likely location of a tornado. This information helps viewers judge whether or not they are likely to be affected by a tornado and, if so, helps them know how quickly they must decide to take action. 
Attention should be paid to the way in which weather broadcasters' actions influence viewers. For example, when the broadcaster steps out of the view of the camera, he or she may still verbally explain radar images, but the images are left open to be interpreted by the viewer, who may or may not be able to make accurate inferences from the images. Facial expressions that communicate the broadcaster's own emotional response to the situation also are lacking. Camera shots without a weathercaster on screen can become more necessary during extended periods of severe weather television coverage or where resources do not allow a second weathercaster's assistance. Do the hand gestures, facial expressions, or other nonverbal aspects of communication between the weather broadcaster and viewers affect whether or not a viewer will take shelter? It is this question that prompted the researchers to consider whether or not the presence of the weathercaster on-screen has a significant influence on viewers' risk perception and preventative behavior.

\section{Background literature}

\section{a. Risk perception and response to severe weather}

There is a long tradition of research linking risk perception with the intention to take some protective action. Lines of theory supporting this association include Protection Motivation Theory (Rogers 1975; Floyd et al. 2000) and the Protection Action Decision Model (Lindell and Perry 2004; Lindell and Hwang 2008). Past research indicates that the perception of a threat's severity and the danger one associates with a storm have a strong influence on decisions made during hazardous situations - such as hurricanes or tornadoes (Baker 1979; Riad and Norris 1998; Mitchem 2003; Schmidlin et al. 2009). For example, Baker (1979) and Riad and Norris (1998) found that people who expected a hurricane to be "bad" were much more likely to evacuate prior to the hurricane than those who did not perceive as much risk. Similarly, people who felt that they were in danger from a tornado also were more likely to seek shelter than people who did not feel in danger (Mitchem 2003; Schmidlin et al. 2009; Chaney and Weaver 2010). The role of risk perception holds true in actual as well as hypothetical situations. The perceived likelihood of impacts as well as confidence in warning information were both significant in explaining one's expectation to evacuate in a hurricane (Arlikatti et al. 2006). Perceived risk of negative impacts also was significantly related to taking protective action to mitigate multiple other natural hazards (Lindell and Hwang 2008).

Several studies have suggested that weathercasters may be effective motivators to a viewer seeking shelter from a tornado. For example, 57\% of respondents in one study reported that what they saw and heard on television prompted their protective action (Brown et al. 2002). In the same Moore, Oklahoma, tornado, more than half of respondents cited television as their reason for taking protective action (Comstock and Mallonee 2005). An overwhelming majority of respondents surveyed by Hammer and Schmidlin (2002) used television as their warning source, and $35 \%$ said that television was their reason for seeking shelter. Many respondents in that study specifically mentioned advice given by Gary England, a long-time local weathercaster in the Oklahoma City area, as their reason for taking protective action. Another study found that the intention to take shelter during a tornado warning was more dependent on trust and the relationship an individual developed with their local weathercaster than whether they believed their home would be safe in strong winds or a tornado (Sherman-Morris 2005). These studies established relationships between the weathercaster's advice and protective action-taking, and between risk perception and taking protective action. Building on these existing relationships, we further examine the influence of a television weathercaster on the formation of risk perceptions and the decision to take shelter when viewing a severe weather broadcast.

\section{$b$. The influence of the on-screen messenger}

Studies cited above make it clear that in the case of severe weather, a primary messenger is the weathercaster. He or she serves as an expert upon whom a viewer can depend for accurate warning information (Wilson 2008), and as a closer acquaintance to whom one can turn to for warning confirmation (ShermanMorris 2005). Because much of the communication between two people is non-verbal, a broadcaster's hand gestures, facial expressions, and other physical motions are used by the viewer to make sense of, and respond to, the weather situation (Cassell et al. 1998; Beattie and Shovelton 1999; Mogg and Bradley 1999; Anderson et al. 2003; Green et al. 2003; Liddell et al. 2005). The processing of body language from communicated information can be considered more of an 
unconscious process. A viewer pays particular attention to facial expressions that convey threat (angry or fearful expressions), and that information is processed automatically (Mogg and Bradley 1999; Anderson et al. 2003; Green et al. 2003; Liddell et al. 2005). Factors such as how an individual feels about the messenger, or qualities of the imagery used to communicate the message, can help to generate an emotional response. These emotional, or affective, reactions to danger can be very effective at influencing response or memory of the event (Slovic et al. 2005). Thus, reasoned decisions are not always required to respond immediately to a threatening situation (Anderson et al. 2003; Liddell et al. 2005). These studies imply that viewers could have an automatic emotional response to portrayed anxiousness about the threatening weather situation. If the weathercaster is in front of the camera during severe weather, observation of this non-verbal communication can take place. If not, then viewers may lose a lot of important information.

Even though intense facial expressions lead to a more automatic response, this may come at the expense of the ability to recall detailed information (Anderson et al. 2003). Threatening expressions also may require increased processing. Green et al. (2003) documented increased viewing time and increased scanning extent for threat-related facial expressions, meaning that more time and effort were spent gathering as much information about the situation as possible. The studies discussed thus far have excluded hand gestures from body language, but for the weathercaster, communication modes beyond the face are essential parts of their communication. More recent research has indicated that hand gestures can influence where attention is paid during a weathercast (Drost et al. 2015). Listeners retain information such that information given by gestures is integrated into memory just as much as what is spoken; gesture and spoken word interact to form one memory (Cassell et al. 1998). Beattie and Shovelton (1999) advanced the notion that hand gestures are an effective complement to spoken communication by studying the types of information best aided by gestures. They found that respondents' memory of characteristics such as size, shape, number, movement, and relative action was significantly improved when both audio and visual cues were present. Audio and visual cues are common during severe weather coverage as a weathercaster tries to communicate a storm's attributes to explain possible danger. However, gestures also may have a distracting influence on the viewer. For example, in two weathercasts (one with gestures and one without), viewers who saw the video with gestures spent more time looking back and forth among elements such as the forecast, the weathercaster's hands, and the weathercaster's face, possibly indicating confusion (Drost et al. 2015). Gesturing in a weathercast was not shown to influence retention (Drost et al. 2015). However, when gestures and the verbal message did not match, the mismatch did alter an individual's ability to recall a story they had watched (Cassell et al. 1998). Individuals can process visual and auditory messages simultaneously if the two do not contradict (Anderson, 2000). In memory research comparing visual and auditory memory tasks, visual information is often superior; however, the outcome may depend on the type of task or the nature of the stimulus. Work by Cohen et al. (2009) demonstrated consistent inferiority of auditory memory over four experiments, although other experiments suggested that visual memory was better over a longer interval-while the two were equal (Bigelow and Poremba 2014), or even that auditory memory had an edge, in the very short term (Jensen 1971). In terms of recall of weather information, a higher percentage remembered weather conditions from a television forecast compared to radio or newspaper (Hyatt et al. 1978); however, the three media are not directly comparable in terms of communicating a weather message via visual or auditory means. Recent research found that recall of tornado warning information was highest when no pictures were displayed with it, regardless of whether the content was presented as audio or written text (Nasco and Bruner 2008). Therefore, studies regarding influence of the on-screen messenger have produced mixed results, where messages that convey emotion can be powerful, but audio and visual components of a message can work to either reinforce or detract from the intended message.

\section{c. The influence of graphical elements of a severe weather message}

Graphical elements of a weather message have been shown to influence how the message is perceived or understood. For example, research has shown that respondents had trouble interpreting the hurricane cone of uncertainty, which may have influenced response during Hurricane Charley (Broad et al. 2007). The use of the rainbow color palette in mapping and 
weather imagery has been the focus of criticism in that the scale is not intuitive (Light and Bartlein 2004; Borland and Taylor 2007; Phipps and Rowe 2010). In one study, respondents who answered questions about a green-scale radar image did respond more accurately than respondents who viewed a rainbow-colored radar image (Bryant et al. 2014). This was especially true for respondents with relatively less meteorological experience. Other work has shown that the properties of a storm surge forecast graphic with a blue color palette may have made it more difficult to interpret, but significant differences among other multi-hued color palettes were not found (Sherman-Morris et al. 2015). Lowe (1999) also demonstrated that meteorology students' extraction of information from an animated weather map was influenced by the perceptually salient aspects of the display, including the movement of the features on the map more so than information that was thematically important. Often, a viewer's ability to make accurate inferences from a scientific map, such as a radar image, is affected by the knowledge they possess in that subject area (Allen et al. 2006; Hegarty et al. 2010). Research participants with greater knowledge of weather processes and map reading skills have tended to make more accurate interpretations from weather maps (Allen et al. 2006; Hegarty et al. 2010). As was noted in the Lowe (1999) study, experts and non-experts alike can be hindered by distractions when attempting to make accurate inferences from maps (Canham and Hegarty 2010; Fabrikant et al. 2010). Similar to the non-verbal elements of the message discussed above, visual elements may or may not help convey the intended message - and how visual elements affect processing varies between expert and non-expert users.

Given the potential importance of verbal and nonverbal aspects of severe weather coverage, this study had three goals. First, it sought to determine whether the presence of the weathercaster on-screen influenced risk perception or the intention to take protective action. Second, the study sought to better understand whether the imagery itself would influence perception or intended behavior, with or without the weathercaster on screen to explain it. Related to this goal, it measured how much viewers knew about the velocity radar image. Finally, the study sought to examine the influence of some of the other visual and audio characteristics of the severe weather coverage on factors such as risk perception, intended action, and accuracy of recall.

\section{Data and methods}

To meet these goals, a survey ${ }^{1}$ with an experimental treatment was created to measure the influence of an on-screen weathercaster on the respondents' likelihood for taking action, risk perception, trust in the weathercaster, and accuracy of retained information. Severe weather coverage from an actual severe weather outbreak was presented to participants during the survey. Video clips from the severe weather coverage were modified, such that one clip would have a weathercaster on-screen presenting the information and the other clip would have the same information presented without the weathercaster on-screen. Whereas it is ideal to measure whether or not an individual has taken action following an actual event, a large body of psychological literature supports the use of intended behavior in survey research as a precursor to an actual behavioral response (Ajzen 1991; Fishbein and Yzer 2003). A hypothetical event also is often the only way to experimentally control conditions. Behavior and other factors, such as risk perception, may vary somewhat between a hypothetical scenario and a real event. However, intended response and risk perception have been used repeatedly to study the response to hazardous weather events (e.g., Drobot et al. 2007; Schultz et al. 2010; Ripberger et al. 2015), and research on hurricane evacuations has demonstrated similarity between response to hypothetical situations and actual behaviors (Whitehead 2005; Kang et al. 2007).

\section{a. Video clips}

Archived television coverage from previous severe weather broadcasts provided a better option (than live coverage) for several reasons, including 1) to account for realistic emotion portrayed by the weathercaster, 2) to show an experienced weathercaster to participants, and 3) to show a weathercaster with whom participants might be familiar. Choosing a pair of severe weather coverage clips, such that only the presence or absence of the weathercaster changed between the two videos, proved to be quite challenging.

James Spann, Chief Meteorologist at ABC 33/40 in the Birmingham, Alabama, market, gave permission to use his archived severe weather coverage. Many hours of video had been recorded and uploaded to YouTube (www.youtube.com/) from recent severe

\footnotetext{
1 The survey can be viewed online at ksmorris.geosci.msstate.edu/ OnOffScreenSurvey.html.
} 
weather outbreaks. Criteria were established for a certain portion of the archived coverage to be used. The ideal on-air clip would have been at least 30-s long (preferably longer) and included radar reflectivity images and the weathercaster, but with no data boxes, icons, or animation of radar sweeps or radar images. The off-air clip would have been identical to the on-air clip except that James Spann would be missing from the video. Separate on- and off-screen video clips that were identical visually and in duration (that also met all of the criteria listed above) were not found. Audio was not considered a part of the original criteria because it was assumed that, for the one pair of clips, the audio from the on-screen clip would be superimposed to the off-screen clip (eliminating unwanted variance). We chose a reflectivity video clip and a velocity clip because we had planned to examine if radar type led to any differences in the study variables. Although audio from on-screen clips was superimposed on the offscreen clips for both pairs, the audio varied between radar types. Differences in audio are discussed below.

The first set of clips was 13-s long, and included a still image of radar reflectivity with a red tornado warning box behind the reflectivity image and a white trapezoid signifying the areas that were most likely to be affected by the storm (Fig. 1). Three cities also were visible: Hamilton, Hackleburg, and Hodges. This set of clips will hereafter be referred to as the $H R$ videos. The second set of clips was 22-s long, included a still image of radar storm-relative velocity, and included a rotating white line that symbolized a scan of the radar. Two cities were visible (Boley Springs and Sandtown), and a third city (Oakman) was mentioned with very strong words of caution. The second set of clips will hereafter be referred to as the $B V$ videos. Previous studies using videos for experimental testing had videos that were much longer. Auter (1992), Cassell et al. (1998), and Hartmann and Goldhoorn (2011) used videos that were $>7 \mathrm{~min}$, on average. The HR videos are much shorter than desired, but provided the best, realistic video of coverage that could be compared. Videos also depicted different locations. There were two clips from the Hamilton area and two from the Boley Springs area - each with an on-screen weathercaster and an off-screen weathercaster. Both locations experienced tornadoes during this event. Survey questions about familiarity with the area and the location most likely to experience a tornado provided no evidence that this influenced the results.
The graphics shown in the HR and BV videos are very different in appearance, with the HR video displaying a large amount of red along with a smoothed hook-shaped radar signature. On the other hand, the BV video displays predominantly green and gray pixels with a small area of red pixels. Based on visual differences, along with viewers' more frequent experiences with reflectivity images, we expect-ed that a difference may exist in risk perception between the two image types. However, the difference in the audio message made it impossible to isolate any differences in perception or behavior associated solely with image type (reflectivity versus velocity). A more significant difference between the two videos was whether the word "tornado" was used to describe the threat. In the BV video, Spann called the danger a "thing" (with a very strong inference that it was a tornado). However, in the HR video, he directly called it a "tornado." A transcript of the two videos follows.

HR video: "Lord, look at that. Again, there you go. Uh, that's your tornado right there that is very close to downtown Hamilton. Uh, this thing has crossed over Interstate 22 and it's cutting right across the northern part or maybe very close to downtown Hamilton."

BV video: "It's racing. I'd say it's moving probably at $50-60 \mathrm{mi}$ an hour. And again, this is a small community called Boley Springs right here. Uh. And then ultimately, it's g-. The next really sizeable municipality in the path of this thing is Oakman. And Oakman has been hit so many times over the years with tornadoes. They know it well and they should know this drill, but if you live anywhere near Oakman or Corona..."

Considering the two video clips' differences in both visual and audio message elements, there are several key factors that may influence risk perception and the intention to take protective action. These include whether a place at risk was labeled on the map, whether a place was mentioned aloud by the weathercaster, how specifically the threat was discussed (i.e., if it was called a tornado), how well the image visually confirmed the threat, and use of other language of emphasis. As the results are presented below, we indicate where significant differences were found and discuss which of the preceding factors may partially explain the differences. 


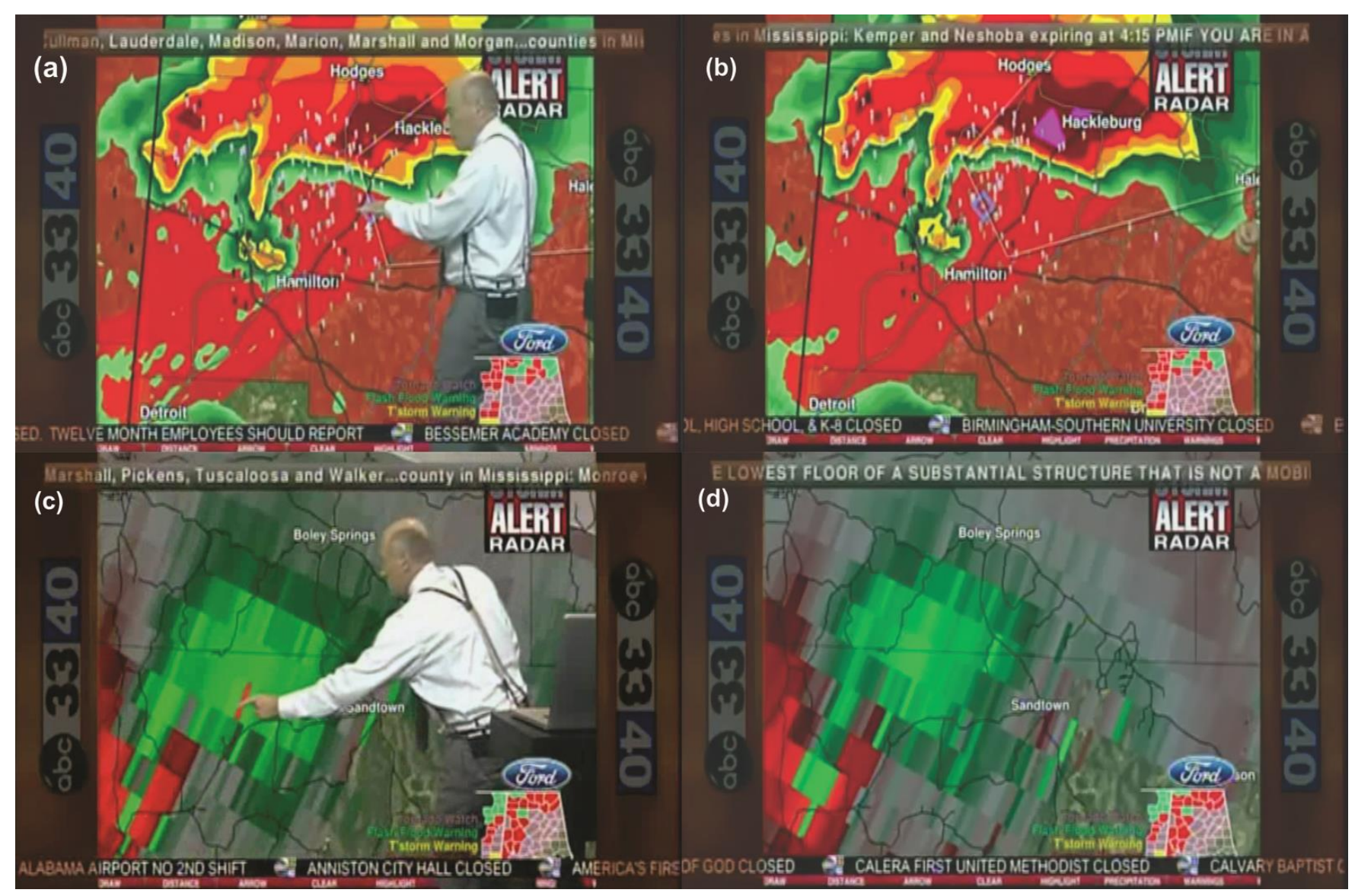

Figure 1. Sample screen shots from four video options used in the survey: (a) HR video, on-screen, (b) HR video, off-screen, (c) BV video, on-screen, and (d) BV video, off-screen. Links to the videos are available here for (a), (b), (c), and (d). Click image for an external version; this applies to all figures hereafter.

\section{b. Survey design}

The survey was designed to obtain information from all respondents about their use and disposition toward weather information, their demographic characteristics, their perceived risk from the severe weather video they viewed, and their trust in the weathercaster viewed during the survey. Six questions, adapted from Colquitt et al. (2007), were used to assess the respondents' trust of the weathercaster. A five-point scale was used for all questions with ratings where only the endpoints were defined. The five-point scale was selected due to the familiarity of the typical Likert-type scale, which ranges from "Strongly Disagree" to "Strongly Agree." Two groups of questions included ratings with these exact endpoints. Other scales also used five points to remain consistent throughout the survey. SurveyMonkey®, the online service through which the survey was delivered, randomly assigned each participant one of the four clips. Respondents were asked a series of risk percep- tion, behavioral intention, and accuracy questions that were based on the video clip received, as well as a group of questions that probed their overall risk perception.

Overall risk perception questions, which were not location specific, asked respondents to rank the storm or situation's scariness, dangerousness, and severity. These questions referred only to the "storm" or "severe weather situation" in the video clip, and did not refer to any individual places. These questions were identical for all respondents. A non-locationspecific behavioral intent question asked how likely they would be to seek shelter from the storm shown in the video. Location-specific questions varied based on which video clip the respondent viewed and the locations portrayed in it. This video-specific part of the survey was designed to evaluate how well information from the videos was retained and to get a more detailed level of perceived risk and behavioral intent. Respondents were asked to rate the severity of damage possible from the storm, and the likelihood of a direct 
hit to two cities in each video (Hamilton and Hodges in the HR video clip, and Sandtown and Oakman in the BV video clip). They also were asked how likely they would be to call or alert someone if the person lived in each of the cities. The four locations were selected because they represented factors that may influence risk perception - including whether the location appeared to be in or near the path of a tornado and if the place was included in the verbal message or not. Accuracy of information retained from the videos was based on three questions with objectively correct answers for the HR video, and two questions for the $\mathrm{BV}$ video. The survey allowed the following research questions $\left(\mathrm{Q}_{\#}\right)$ to be answered and hypotheses $\left(\mathrm{H}_{\#}\right)$ to be tested.

$\mathrm{Q}_{1}$ : How will risk perception and preventative behavior vary among respondents who saw the HR and $\mathrm{BV}$ videos?

$\mathrm{Q}_{2}$ : What differences exist within and between the two video locations?

$\mathrm{Q}_{3}$ : Can the verbal or visual message factors described above explain any differences found?

$\mathrm{Q}_{4}$ : Can respondents who watched the BV video describe what that radar image means?

$\mathrm{H}_{1}$ : Risk perception will be different between respondents who watch the on-screen and off-screen videos.

$\mathrm{H}_{2}$ : Intended preventative behavior will be different between respondents who watch the on-screen and off-screen videos.

$\mathrm{H}_{3}$ : Accuracy of recall will be different between respondents who watch the on-screen and off-screen videos.

$\mathrm{H}_{4}$ : Intended preventative behavior will be related to trust in the weathercaster, perceived risk for that location, accuracy of recall of information, and video watched.

\section{c. Sample}

There were three distinct samples taken. The first sample (Sample 1) was obtained through an Internet announcement by James Spann. The randomization feature in the Sample 1 survey was not correctly set up to record whether a respondent received the video clip with the weathercaster on- or off-screen. This made it impossible to use these responses for inferences about the weathercaster's effect on viewers. Therefore, additional surveys were obtained. A second sample (Sample 2) was recruited from a physical geography class. The third sample (Sample 3) was recruited from a second Internet announcement by James Spann, supplemented by an announcement from one of the researchers on social media. Roughly one month passed between the first announcement and the third. In these three sampling periods, 1935 surveys were attempted, although owing to incomplete responses, only about $43 \%$ could be used. Sample 1 provided 486 completed surveys, Sample 2 provided 22, and Sample 3 provided 321. The remaining 1106 surveys were not used owing to lack of data.

The average age of respondents was 38 years. More women $(62.1 \%)$ participated in the study than men $(37.9 \%)$. Also, approximately $96 \%$ of people indicated that they identified most with being white. Other and black followed with close to $2 \%$ each. Women and people identifying as white were overrepresented in the samples. Education was more representative than the other demographic characteristics. Approximately $14 \%$ of respondents reported no education beyond high school $(1.8 \%=$ some high school and $12.1 \%=$ high school graduate). The greatest frequency of respondents reported some college $(40.5 \%)$, followed by $29.1 \%$ with a bachelor's degree, and $16.4 \%$ with an advanced degree. None of the samples appeared to be familiar enough with the area to bias the results. Average familiarity was 2.58 and 2.29 for the Hamilton and Boley Springs area, respectively-both of which were below the mid-point. All but Sample 2 were familiar with the weathercaster in the video. A majority of respondents watched James Spann at least several times per week. For additional information about the sample, and responses to questions not discussed below, please see Lea (2012).

\section{Results and analysis}

\section{a. Risk perception and preventative behavior based on video clip}

One of the research questions asked how risk perception and intended preventative behavior would vary between individuals who saw a video clip of a reflectivity image (HR) in the Hamilton area compared to those who viewed a video clip with a velocity image 
(BV) in the Boley Springs area. There was a significant difference found in the overall risk perceived when respondents viewed the HR video compared to the $\mathrm{BV}$ video $(p<0.001)$. The overall likelihood to take shelter from the storm in the video was also significantly different $(p<0.001)$ depending on which video clip the respondents received. Respondents who received the HR video reported being more likely to seek shelter from the storm (4.72) over those who viewed the BV video (4.43). There are several possible explanations for these differences between the videos. In addition, responses differed based on location within each video clip. Each of these differences and potential reasons are discussed below.

\section{1) BV VIDEO CLIP}

The two locations on the BV video about which respondents reported their perceived risk were Oakman and Sandtown. The mean risk for Oakman was 3.94, whereas Sandtown was only 3.00 (Fig. 2). This difference between locations was significant ( $p$ $<0.001)$. Recall that in this video, Oakman was emphasized verbally and the weathercaster mentioned that Oakman has experienced tornadoes in the past and viewers know what to do. Oakman did not appear on the map used in the video. Sandtown was labeled on the map but was not addressed either verbally or by pointing. Boley Springs was mentioned and alluded to as a possible city in the path (both by hand gesture and verbally). Sandtown was not mentioned, even though it does visually appear closer to the area where the rotation existed. The path drawn on the video clip by the weathercaster had the tornado moving between Boley Springs and Sandtown. Oakman was located outside of the mapped area, but this did not appear to make a difference. Risk did not vary significantly for either location as a function of the weathercaster's presence on-screen, which highlights the importance of the verbally communicated message even when the person delivering it cannot be seen. Similar to the risk perception ratings, respondents were significantly ( $p$ $<0.001)$ more likely to alert a friend or relative of the approaching tornado if they were in Oakman (4.64) rather than Sandtown (3.79).

There were two characteristics in the BV video that provided visual evidence of the tornado threat: the path on the map that the weathercaster drew and the adjacent red and green of the radar image. To probe whether the colors would serve as visual evidence of a tornado for respondents, we asked them if they knew what the colors on a velocity radar product indicated. About three quarters of respondents $(73.6 \%)$ believed that they did. When given the option to explain the colors, fewer than half $(43.7 \%)$ of all respondents were able to do so correctly. An approximately equal number of respondents gave an incorrect definition $(28.8 \%)$ as those who chose not to respond or who gave a response indicating that they did not know $(27.4 \%)$.

\section{2) HR VIDEO CLIP}

Two locations in the HR video also led to very different levels of perceived risk. Based on the perceived likelihood of experiencing a direct hit and the perceived severity of the damage, Hamilton was rated 4.04, whereas Hodges was rated 2.77-a significant difference $(p<0.001)$. Hamilton was mentioned in the video ("That's your tornado right there that is very close to downtown Hamilton..."). Hodges was not mentioned verbally in the video, but was labeled on the map in an area of the radar with high reflectivity. The differences in the BV video (previously discussed) suggested the power of the audio. It is therefore not surprising that the city mentioned as being very close to the tornado would prompt higher estimates of likelihood and severity of damage. A similar pattern was observed for behavioral intention whereby respondents would be more likely to alert someone in Hamilton (4.68) than in Hodges (3.39). This difference also was significant $(p<0.001)$.

Visually, the HR video provided more evidence of a tornado threat than the BV video. The weathercaster drew a circle to indicate rotation near Hamilton. The HR video clip showed a warning polygon, which moved to include Hodges during the video clip with the weathercaster off-screen. There also was considerably more red on the HR video image. Additionally, the radar image showed a hook echo north of Hamilton; however, we did not probe the respondents' ability to explain what this meant. Therefore, it is unclear whether the radar provided any additional visual evidence beyond the warning polygon. The most important element of the HR video clip is most likely the weathercaster using the word tornado, and associating it with a specific location-downtown Hamilton. The HR video clip referred to the threat directly as a tornado whereas the BV video clip did not. Finally, the weathercaster began the clip by saying "Lord, look at that...", which could have provided another verbal cue that this was a threatening situation. 


\section{Average responses for each location on vs. off}

\section{screen}

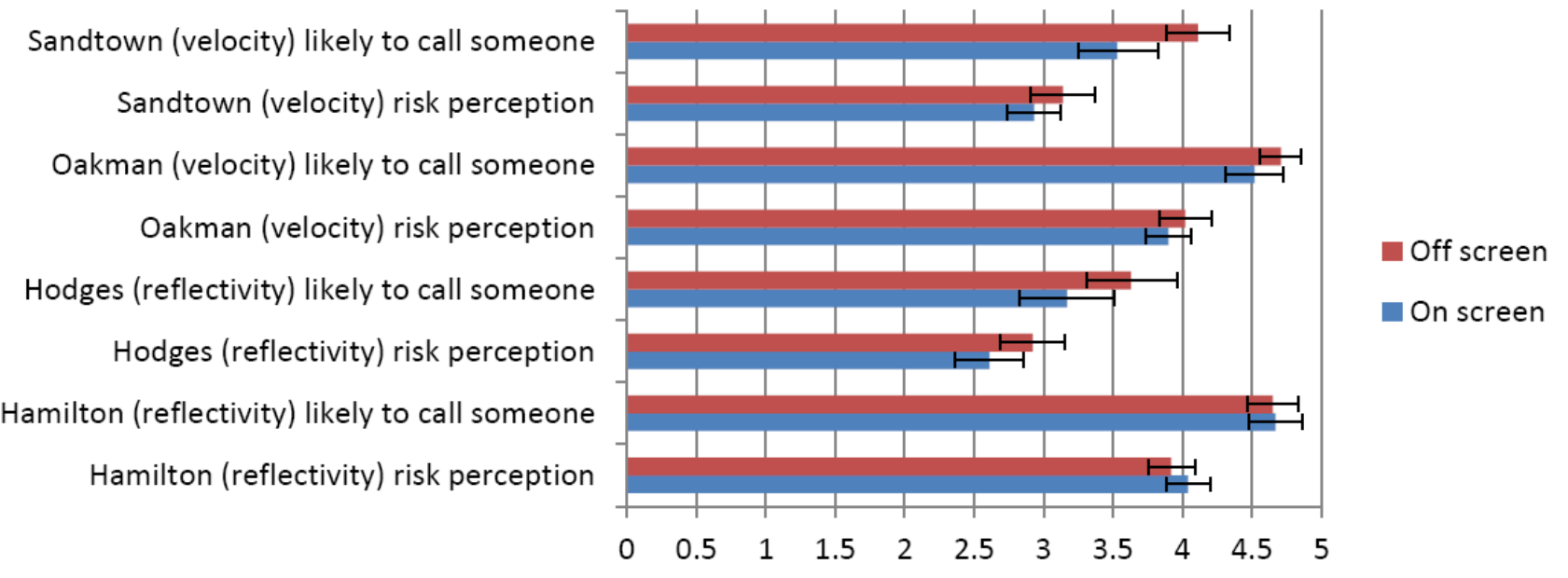

Figure 2. Location-specific risk perception responses and reported likelihood of calling to alert someone about the storm.

These factors very likely contributed to the HR video clip's overall higher perceived risk of 4.35 (out of 5), compared to the perceived risk of 4.08 from the BV video clip. Respondents who viewed the HR video also were much more likely to believe that there was a confirmed tornado with the storm. Two-thirds (66.1\%) replied "yes" there was a confirmed tornado in the HR video compared to only one-third $(33.5 \%)$ who believed there was a confirmed tornado in the BV video. Among the respondents who viewed the BV video clip, $45.5 \%$ replied that they did not know if there was a confirmed tornado.

\section{b. Weathercaster on-screen versus off-screen}

Hypotheses 1 through 3 proposed that there would be significant differences in risk perception, preventative behavior, and accuracy of recall between respondents who viewed the video clips with the weathercaster on-screen versus off-screen. Because significant differences were found in risk perception and preventative behavior between the two video clips, the HR and BV samples were examined separately. A trend was observed in which off-screen videos led to a higher risk perception for three of the four locations. When tested, none of these differences were significant; however, the difference for Hodges approached significance [Hamilton, 4.04 on-screen versus 3.92 off-screen ( $p=0.284)$; Hodges 2.61 on-screen versus 2.92 off-screen $(p=0.082)$; Oakman 3.90 on-screen versus 4.02 off-screen $(p=0.369)$; Sandtown 2.93 onscreen versus 3.14 off-screen $(p=0.221)]$. In the offscreen HR video, the polygon location moves such that Hodges is much more directly within the polygon. This could help to explain why the risk perception values for Hodges are closer to being significantly different than for the remaining locations. There were no significant differences found in overall risk perception in either video clip based on whether the weathercaster was present on-screen versus off-screen ( $p=0.776$ for HR and $p=0.893$ for BV; see Fig. 3).

An interesting pattern also emerged in preventative behavior in which the off-screen videos resulted in higher likelihood to call someone to alert them of the storm for all but one location. For two locations where risk was perceived to be lower, Sandtown and Hodges, the on-screen/off-screen difference was significant ( $p$ $=0.008)$ or marginally significant $(p=0.054)$. For the two locations where risk was perceived to be higher, Hamilton and Oakman, the on-screen/off-screen variable did not lead to significant differences in likelihood to call to alert someone ( $p=0.666$ for Hamilton and $p=0.364$ for Oakman). Whether respondents viewed the weathercaster on-screen or off-screen made no difference in likelihood to take shelter for either video clip ( $p=0.678$ for $\mathrm{BV}$ and $p=0.701$ for HR).

Finally, based on evidence from past studies of video recall, hypothesis 3 proposed that accuracy of recall would be different based on whether a respon- 


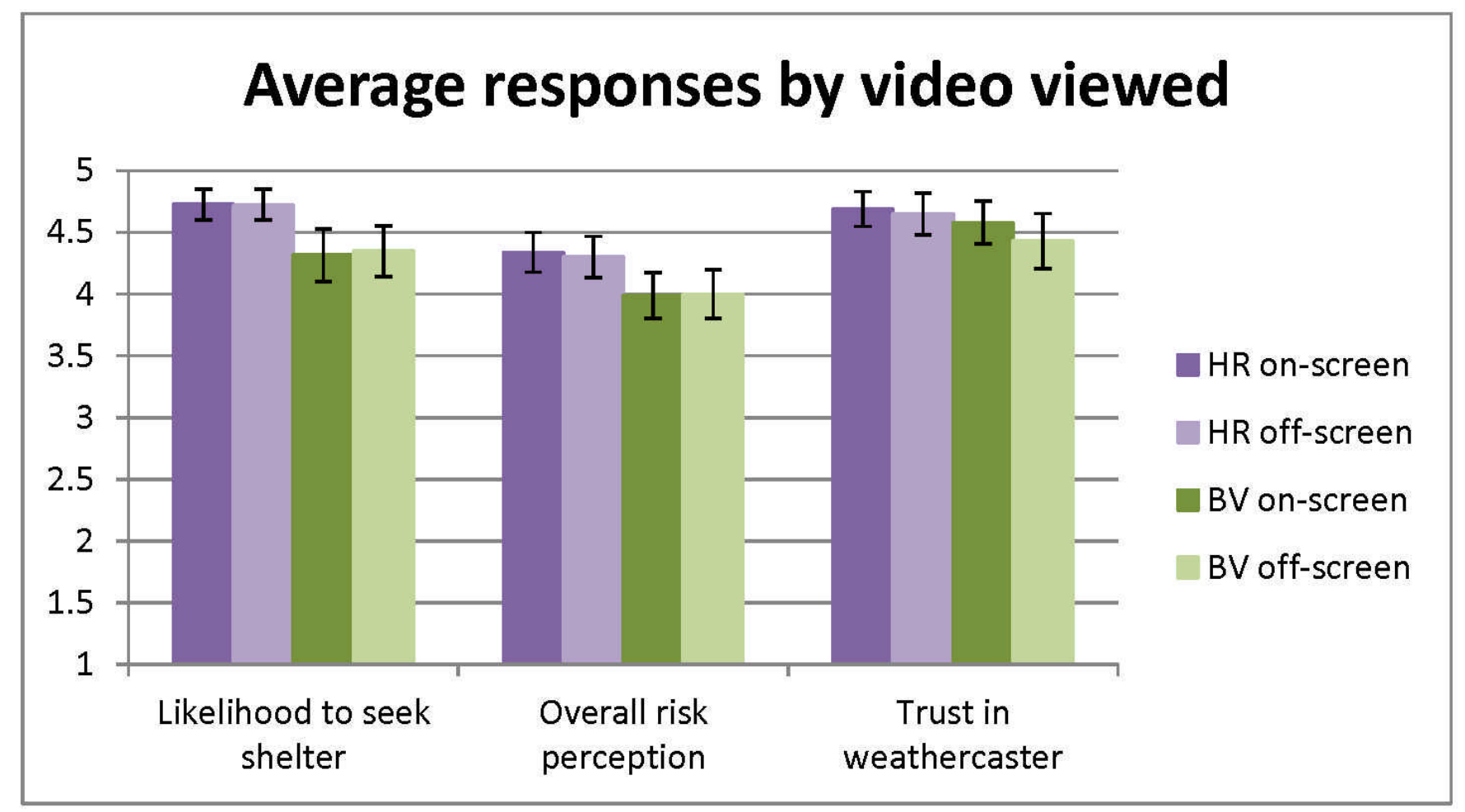

Figure 3. Responses on three survey variables grouped according to video viewed.

dent viewed the weathercaster on-screen or off-screen. Differences in accuracy between respondents viewing the video with the weathercaster on-screen $(56.5 \%)$ and those who viewed the video with the weathercaster off-screen $(50.8 \%)$ were not statistically significant $(p=0.103)$.

\section{c. Correlation and regression analysis}

Results discussed in this section are directed toward hypothesis 4 , regarding the variables expected to correlate with intended behavior. Initially, a bivariate Spearman rank correlation analysis was performed on all demographic variables in the survey and each of the variables that they might explain (i.e., overall and location-specific risk perception, accuracy, trust, overall likelihood of taking shelter, and likelihood of calling to alert someone in the path in each location). Demographics were not related to many of the dependent variables. Education was related (negatively) only to overall risk perception and the likelihood of calling to alert someone in Sandtown. Age was related positively to accuracy of recall $(0.101, p=0.005)$ and negatively to the likelihood of calling to alert someone in Hodges $(-0.105, p=0.049)$. Race was related (positively) only to the likelihood of calling to alert someone in Hodges $(0.108, p=0.045)$. The lack of consistent relationships between demographic variables and those variables they might help explain, and the low values of the correlation coefficients (the largest was -0.15 between education and likelihood of calling Sandtown), led us to omit demographic variables from further analysis.

More significant relationships were found among variables that have a record of correlation in the literature, such as trust, risk perception, and the likelihood of taking action. Trust in the weathercaster has been associated with the intention to take action during severe weather in previous research (ShermanMorris 2005), and the relationship between risk perception and taking protective action was discussed above. Our results indicate that trust was significantly related to recall accuracy $(0.079, p=0.029)$, overall risk perception $(0.223, p<0.001)$, and overall likelihood of taking shelter $(0.206, p<0.001)$, as well as likelihood of calling to alert someone in Sandtown (0.101, $p=0.045)$, Oakman $(0.159, p=0.001)$, and Hamilton $(0.152, p=0.003)$. It was not related in Hodges, where perceived risk was the lowest. Trust in the weathercaster in the video was very high overall (average of 4.54 out of 5), and did not vary between individuals who viewed the video with the weathercaster on-screen and those who viewed the video with the weathercaster off-screen $(p=0.313)$. Similarly, no 
difference in trust was found between respondents who viewed the two types of radar products (see Fig. 3).

Overall risk perception was significantly and positively correlated with overall likelihood of taking shelter in the viewed storm $(0.54,<0.001)$. Additionally, the perceived risk for each location was significantly and positively correlated with the intended likelihood of the respondent calling to alert someone in that location of the impending storm. Correlation values included $0.52(p<0.001)$ for Sandtown, $0.34(p<0.001)$ for Oakman, $0.666(p=0.000)$ for Hodges, and 0.373 $(p<0.001)$ for Hamilton. Respondents who reported being likely to call someone in one of the two locations to alert them of the storm also tended to be likely to call someone in the other location they were asked about. Correlations were $0.343(p<0.001)$ between Hamilton and Hodges' likelihood to call and 0.199 ( $p$ $<0.001)$ between Sandtown and Oakman's likelihood of calling. Respondents were only asked about the two locations in the video they viewed.

Accuracy of recall was significantly related to the overall likelihood of seeking shelter $(0.098, p=0.007)$, and the likelihood of calling to alert someone in Oakman $(0.145, p=0.003)$ and Hodges $(-0.125, p=$ $0.024)$. It also was related to perceived risk at each location-positively for Oakman and Hamilton (the locations with higher perceived risk) and negatively for Sandtown and Hodges (locations with lower perceived risk).

Following an examination of individual correlations, an ordinal regression to predict overall likelihood of taking shelter in the storms viewed was run on trust, overall risk perception, accuracy of recall, whether the weathercaster was on- or off-screen, and type of radar shown. An ordinal regression was selected because the dependent variable, overall likelihood of taking shelter, was reported in discrete values from one to five and the responses were very non-normally distributed. Ordinal regression allows one to determine how likely (as measured by the log-odds) one might expect an increase in the dependent variable from one category to the next based on the independent variable. In the first model run, the overall risk perception, accuracy of recall, and type of video were significant. Trust and whether the weathercaster was on- versus off-screen were not significant. The model was a significant improvement over the intercept-only model, and the combination of variables resulted in a Nagelkerke pseudo $R$-square value of 0.456 . A final model run without trust and on-screen/off-screen yielded a Nagelkerke pseudo $R$-square value of 0.385 with all independent variables significant at $p<0.001$; the exception was accuracy, which was significant at $p=$ 0.017 .

Similar regressions were performed using likelihood of calling to warn someone about the storm in the video as the dependent variable. In three of the four locations (Hamilton, Hodges, and Oakman), only perceived risk was significant in a model including perceived risk, accuracy of recall, trust in the weathercaster, and weathercaster presence on- or off-screen. For Sandtown, risk perception, trust, and on- or offscreen presence were all significant. It is unclear why these differences would exist for this location.

\section{Discussion}

The results presented above show that respondents were able to discriminate among areas of higher and lower levels of perceived risk in each type of video when the question focused on particular locations. That is, in the HR video, perceived risk was lower for Hodges than Hamilton. In the BV video, the risk for Sandtown was rated lower than Oakman by a similar amount. These differences likely were driven by differences in what the weathercaster said during the clips, more than the visual elements of the video. Both locations with higher perceived risk (Hamilton and Oakman) were mentioned by the weathercaster, while the two places with lower perceived risk were not. In the case of Oakman, the location with the higher perceived risk was not even labeled on the map, providing evidence for the power of the spoken message.

Differences also were found between the HR and $\mathrm{BV}$ videos, which also were most likely driven by the spoken message rather than visual elements. Average ratings for risk perception, trust in the weathercaster, and overall likelihood to take shelter were higher for respondents who viewed the HR video than those who viewed the BV video. This was significant for overall risk perception and the reported likelihood of taking shelter if affected by the storm in the video viewed. The transcripts of the videos show that only the HR video explicitly called the "thing" being displayed a tornado. Whether this could have been the underlying cause of differences between the two radar video clips cannot be determined with certainty. However, a much greater percentage of respondents believed there was a confirmed tornado in the HR video $(67.1 \%$ yes, $19.3 \%$ I don't know) than in the BV video (33.5\% yes, $45.5 \%$ I don't know), providing additional evidence that this word choice influenced risk perception. 
The results presented above suggest that the presence of the weathercaster on-screen during the severe weather coverage shown in this project made very little difference in the key response variables measured. For all but Hamilton (in the HR video), scores for perceived risk and likelihood of calling someone to alert them about the storm were higher when the weathercaster was located off-screen. However, the only area where weathercaster presence made a significant difference in responses was in the likelihood of calling to alert someone. For the two locations where perceived risk was lower, Sandtown and Hodges, likelihood to call someone to alert them of the storm was significantly or marginally significantly higher when the respondent watched the video with the weathercaster off-screen.

Accuracy of recall was not significantly different between the two videos or whether the weathercaster was located on- or off-screen. The difference in accuracy among people who viewed the two videos was smaller than expected given a lack of understanding of velocity imagery demonstrated in the responses. The questions were not, however, dependent on knowing anything about either type of radar product. They were designed to test how well the respondents could recall basic information shown on the maps or mentioned by the weathercaster. Accuracy was significantly related to several risk perception and behavioral intention variables, and remained a significant contributor in the model predicting the likelihood to take shelter. An interesting finding regarding accuracy was that its relationship with risk perception changed depending on whether the respondent was judging the risk of the location with the higher perceived risk or the lower perceived risk. That is, the relationship was positive for the higher risk location but negative for the lower risk location. Although there are potential explanations for such a relationship, it also is possible the result was influenced by the specific questions asked. Similarly, the presence of the weathercaster had the most influence on likelihood to call someone to alert them when respondents were asked about the location with lower perceived risk. Respondents who viewed the clip with the weathercaster off-screen had a greater (but not significant) likelihood of calling someone as well as higher risk perception in three of four locations. While intention is most closely related to risk perception, these patterns also may suggest that the audio message had the more powerful effect on the association between a location and its perceived risk. Without specific details in the spoken message, viewers are left to fill in the gaps with other information. This would help explain why the weathercaster's presence was only significant in one comparison involving Sandtown. Although it is not clear why this is the case, it may be that the weathercaster pointing to other locations on-screen may have directed attention away from the locations where the risk was lower. One should not infer from this discussion that this is a bad thing. One would expect the weathercaster to intentionally draw attention toward the more dangerous part of the map being displayed.

Results from the correlation and regression analysis agree with much of the past research on the importance of perceived risk on the intention to take action during severe weather. Risk perception, accuracy of recall, and trust in the weathercaster all were correlated with themselves and behavioral intention variables. That trust did not play a larger role in the regression to predict overall likelihood of taking shelter was somewhat surprising. One explanation may be the almost universally high level of trust in the weathercaster in the videos. This may be the result of the sample being recruited from the weathercaster's own website. It also is possible that trust precedes risk perception in the risk communication and protection motivation process, and in the regression, its impact was diminished by the presence of a risk perception variable.

\section{Conclusions}

The paper sought to test three hypotheses about accuracy of recall, risk perception, and behavioral intention based on whether the respondents viewed a clip with the weathercaster present or absent. A fourth hypothesis proposed relationships among several variables-including behavioral intention, trust in the weathercaster, perceived risk, accuracy of recall of information, and video watched. It also sought to answer research questions regarding how risk perception and preventative behavior vary between respondents who saw two severe weather clips with different radar types and messages. In describing the differences within and between the clips, the paper discussed several possible verbal or visual message factors that may have influenced results.

The most interesting results were found in examining the differences within and between the two videos: HR, which used a reflectivity image to illustrate the tornado risk for the Hamilton, Hodges, and Hackleburg areas; and $\mathrm{BV}$, which used a velocity image to provide warning information for the Boley Springs, 
Oakman, and Sandtown areas. Significant differences were found between the HR video and BV video with respect to overall risk perception and intention to take shelter. Differences in risk perception and intention to take action also were found within each video when respondents were asked location-specific risk perception and behavioral intention questions. There are several likely reasons for the differences found. Although there may be some visual differences between the two video clips based on the radar image used, the more likely explanation is derived from the differences in the verbal message between the HR and BV videos. The HR video was very specific about what (tornado) and where (downtown Hamilton) the threat existed, whereas the BV video was less specific, referring to the threat as a thing and describing the next sizeable location (Oakman) in its path. More respondents believed there was a confirmed tornado in the HR video. This certainly would have influenced risk perception. The responses to the location-specific questions also provided evidence for the strong influence of the verbal message over visual factors. Both of the locations with higher risk perception (Hamilton and Oakman) were locations stated in the verbal message, but only Hamilton was labeled on the map.

The differences in message between the two types of radar images described above made it impossible to determine whether any differences existed in risk perception or intention that could be partially explained by image type. The fact that fewer than half of respondents in this study could explain what the velocity product was showing makes it an important area for future study. Reflectivity often is shown during daily weather, as well as during severe weather coverage. This should lead to better understanding of reflectivity images, but unfortunately, respondents were not asked to describe what that radar image was showing. The results of this study suggest that many message characteristics, planned or unplanned, may lead to differences in perception or behavior. This study should not be used to draw conclusions about the usefulness of one type of radar image or another. However, it provides a useful starting point for future studies to examine the influence of radar imagery in greater depth - with a representative sample of severe weather broadcast viewers and severe weather video clips more carefully controlled for message content and length.

The three hypotheses regarding presence or absence of the weathercaster were not supported. It made very little influence on risk perception, or accuracy, whether the weathercaster was on-screen or off-screen. Hypothesis 2, which proposed differences in preventative behavior based on respondents viewing the weathercaster on- or off-screen, was partially supported based on the significant difference found in intention to call and alert someone in the path of the storm for Sandtown and the marginally significant difference for Hodges. On- or off-screen presence set the limit to what role facial expressions or gestures might play in the variables tested, but it was beyond the scope of the study to examine either in detail. Future studies should examine the influence of these as well as other cues such as tone, rate of speaking, and so on. Hypothesis 4 was supported in that a number of significant relationships were found among the proposed variables. Most of these relationships were already supported in the literature.

When applying the results to the communication of severe weather information, some considerations should be acknowledged. One should not accept this study as proof that it does not matter if the weathercaster is present on-screen or off-screen talking over radar imagery during a severe weather event. It is possible that no influence was found because the length of clips used in testing was not long enough to elicit authentic responses. Other studies using video in testing that resulted in statistical significance were at least 2-min long, but the clips administered in this study were <25-s long. Even though the videos were long enough to lead to other significant differences, the weathercaster may have had more influence if longer clips were used, or if the content was more carefully controlled. It also is possible that the scale used was just coarse enough to prevent differences from emerging. Choosing video clips with such a wellknown and trusted weathercaster also may have had some influence here, but during actual severe weather coverage, viewers likely are to watch the weathercaster they know and trust the most. In the future, video clips should be designed with research in mind in order that all of the issues discussed above can be controlled. This study also did not consider the influence of the weathercaster's presence on individuals with hearing or sight impairments. Because differences in responses likely were due to characteristics of the spoken message that were not always evident in the visual message, future studies examining verbal or visual communication methods should take this part of the population into account. 
Acknowledgments. We thank James Spann, Chief Meteorologist at ABC 33/40 in Birmingham. Without his assistance this study would not have been possible.

\section{REFERENCES}

Ajzen, I., 1991: The theory of planned behavior. Organ. Behav. Hum. Dec., 50, 179-211.

Allen, G. L., C. R. M. Cowan, and H. Power, 2006: Acquiring information from simple weather maps: Influences of domain-specific knowledge and general visual-spatial abilities. Learn. Individ. Differ., 16, 337349, Crossref.

Anderson, A. K., K. Christoff, D. Panitz, E. De Rosa, and J. D. Gabrieli, 2003: Neural correlates of the automatic processing of threat facial signals. J. Neurosci., 23, 5627-5633.

Anderson, J. R., 2000: Cognitive Psychology and Its Limitations. Worth Publishers, 469 pp.

Arlikatti, S., M. K. Lindell, C. S. Prater, and Y. Zhang, 2006: Risk area accuracy and hurricane evacuation expectations of coastal residents. Environ. Behav., 38, 226-247, Crossref.

Auter, P. J., 1992: Psychometric: TV that talks back: An experimental validation of a parasocial interaction scale. J. Broadcast Electron., 36, 173-181, Crossref.

Baker, E. J., 1979: Predicting response to hurricane warnings: A reanalysis of data from four studies. Mass Emergencies, 4, 9-24.

Balluz, L., L. Schieve, T. Holmes, S. Kiezak, and J. Malilay, 2000: Predictors for people's response to a tornado warning: Arkansas, 1 March 1997. Disasters, 24, 71-77, Crossref.

Beattie, G., and H. Shovelton, 1999: Mapping the range of information contained in the iconic hand gestures that accompany spontaneous speech. J. Lang. Soc. Psychol., 18, 438-462, Crossref.

Bigelow, J., and A. Poremba, 2014: Achilles' ear? Inferior human short-term and recognition memory in the auditory modality. PloS ONE, 9, e89914, Crossref.

Borland, D., and R. M. Taylor II, 2007: Rainbow color map (still) considered harmful. IEEE Comput. Graph., 27, 14-17, Crossref.

Broad, K., A. Leiserowitz, J. Weinkle, and M. Steketee, 2007: Misinterpretations of the "Cone of Uncertainty" in Florida during the 2004 hurricane season. Bull. Amer. Meteor. Soc., 88, 651, $\underline{\text { Crossref. }}$

Brown, S., P. Archer, E. Kruger, and S. Mallonee, 2002: Tornado-related deaths and injuries in Oklahoma due to the 3 May 1999 tornadoes. Wea. Forecasting, 17, 343353, Crossref.

Bryant, B., M. Holiner, R. Kroot, K. Sherman-Morris, W. B. Smylie, L. Stryjewski, M. Thomas, and C. I. Williams,
2014: Usage of color scales on radar maps. $J$. Operational Meteor., 2, 169-179, Crossref.

Canham, M., and M. Hegarty, 2010: Effects of knowledge and display design on comprehension of complex graphics. Learn. Instr., 20, 155-166, Crossref.

Cassell, J., D. McNeill, and K. McCullough, 1998: Speechgesture mismatches: Evidence for one underlying representation of linguistic \& nonlinguistic information. Pragmatics Cognition, 6 [Available online at www.justinecassell.com/publications/prag\%26cog han dout.pdf.]

Chaney, P. L., and G. S. Weaver, 2010: The vulnerability of mobile home residents in tornado disasters: The 2008 Super Tuesday Tornado in Macon County, Tennessee. Wea. Climate Soc., 2, 190-199, Crossref.

Cohen, M. A., T. S. Horowitz, and J. M. Wolfe, 2009: Auditory recognition memory is inferior to visual recognition memory. Proceedings of the National Academy of Sciences, 106, 6008-6010, Crossref.

Colquitt, J. A., B. A. Scott, and J. A. LePine, 2007: Trust, trustworthiness, and trust propensity: A meta-analytic test of their unique relationships with risk taking and job performance. J. Appl. Psychol., 92, 909-927, Crossref.

Comstock, R. D., and S. Mallonee, 2005: Comparing reactions to two severe tornadoes in one Oklahoma community. Disasters, 29, 277-287, Crossref.

Drobot, S. D., C. Benight, and E. C. Gruntfest, 2007: Risk factors for driving onto flooded roads. Environ. Hazards, 7, 227-234, Crossref.

Drost, R., J. Trobec, C. Steffke, and J. Libarkin, 2015: Eye tracking: Evaluating the impact of gesturing during televised weather forecasts. Bull. Amer. Meteor. Soc., in press, Crossref.

Fabrikant, S. I., S. R. Hespahna, and S. Hegarty, 2010: Cognitively inspired and perceptually salient graphic displays for efficient spatial inference making. Ann. Assoc. Amer. Geogr., 100, 13-29, Crossref.

Fishbein, M. and M. C. Yzer, 2003: Using theory to design effective health behavior interventions. Commun. Theor., 13, 164-183, Crossref.

Floyd, D. L., S. Prentice-Dunn, and R. W. Rogers. 2000: A meta-analysis of research on protection motivation theory. J. Appl. Soc. Psychol., 30, 407-429, Crossref.

Green, M. J., L. M. Williams, and D. Davidson, 2003: Brief report: In the face of danger: Specific viewing strategies for facial expressions of threat. Cognition Emotion, 17, 779-786, Crossref.

Hammer, B., and T. W. Schmidlin, 2002: Response to warnings during the 3 May 1999 Oklahoma City tornado: Reasons and relative injury rates. Wea. Forecasting, 17, 577-581, Crossref.

Hartmann, T., and C. Goldhoorn, 2011: Horton and Wohl revisited: Exploring viewers' experience of parasocial interaction. J. Commun., 61, 1104-1121, Crossref. 
Hegarty, M., M. S. Canham, and S. I. Fabrikant, 2010: Thinking about the weather: How display salience and knowledge affect performance in a graphic inference task. J. Exp. Psychol.: Learn. Mem. Cognit., 36, 37-53, Crossref.

Hyatt, D., 1978: Recall of television weather reports. Journalism Quart., 55, 306-310, Crossref.

Jensen, A. R., 1971: Individual differences in visual and auditory memory. J. Educ. Psychol., 62, 123-131, Crossref.

Kang, J. E., M. K. Lindell, and C. S. Prater, 2007: Hurricane evacuation expectations and actual behavior in Hurricane Lili. J. Appl. Soc. Psychol., 37, 887-903, Crossref.

Lazo, J. K., R. E. Morss, and J. L. Demuth, 2009: 300 billion served. Sources, perceptions, uses and values of weather forecasts. Bull. Amer. Meteor. Soc., 90, 785798, Crossref.

Lea, A. M., 2012: Effects of television weather broadcasters on viewers during severe weather: To be or not to be on-screen. M.S. Thesis, Dept. of Geosciences, Mississippi State University, 98 pp. [Available online at gradworks.umi.com/15/30/ 1530697.html.]

Legates, D. R., and M. D. Biddle, 1999: Warning response and risk behavior in the Oak Grove-Birmingham, Alabama, Tornado of 08 April 1998. Quick Response Report \#116. Natural Hazards Research Applications and Information Center, Boulder, Colorado. [Available by contacting the librarian at hazctr@colorado.edu.]

Liddell, B. J., K. J. Brown, A. H. Kemp, M. J. Barton, P. Das, A. Peduto, E. Gordon, and L. M. Williams, 2005: A direct brainstem-amygdala-cortical 'alarm' system for subliminal signals of fear. Neuroimage, 24, 235243, Crossref.

Light, A., and P. J. Bartlein, 2004: The end of the rainbow? Color schemes for improved data graphics. EOS, 85, $385,391$.

Lindell, M. K., and R. W. Perry, 2004: Communicating Environmental Risk in Multiethnic Communities. Sage Publications, $272 \mathrm{pp}$.

, and S. N. Hwang, 2008: Households' perceived personal risk and responses in a multihazard environment. Risk Anal., 28, 539-556, Crossref.

Lowe, R. K., 1999: Extracting information from an animation during complex visual learning. Eur. J. Psychol. Educ., 14, 225-244, Crossref.

Mitchem, J. D., 2003: An analysis of the September 20, 2002, Indianapolis tornado: Public response to a tornado warning and damage assessment difficulties. Quick Response Report \#161, Natural Hazards Research Applications and Information Center, Boulder, Colorado. [Available by contacting the librarian at hazctr@ colorado.edu.]

Mogg, K., and B. P. Bradley, 1999: Orienting of attention to threatening facial expressions presented under conditions of restricted awareness. Cognition Emotion, 13, 713-740, Crossref.

Nasco, S. A., and G. C. Bruner, 2008: Comparing consumer responses to advertising and non-advertising mobile communications. Psychol. Mark., 25, 821-837, Crossref.

Phipps, M., and S. Rowe, 2010: Seeing satellite data. Public Underst. Sci., 19, 311-321, Crossref.

Riad, J. K., and F. H. Norris, 1998: Hurricane threat and evacuation intentions: An analysis of risk perception, preparedness, social influence, and resources. Preliminary Paper \#271, University of Delaware, Disaster Research Center, 35 pp. [Available online at dspace.udel.edu/bitstream/handle/19716/107/PP271Hurricane\%20Threat.pdf?sequence=1.]

Ripberger, J. T., C. L. Silva, H. C. Jenkins-Smith, D. E. Carlson, M. James, and K. G. Herron, 2015: False alarms and missed events: The impact and origins of perceived inaccuracy in tornado warning systems. Risk Anal., 35, 44-56, Crossref.

Rogers, R. W. 1975: A protection motivation theory of fear appeals and attitude change. J. Psychol., 91, 93-114, Crossref.

Schmidlin, T. W., B. O. Hammer, Y. Ono, and P. S. King, 2009: Tornado shelter-seeking behavior and tornado shelter options among mobile home residents in the United States. Nat. Hazards, 48, 191-201, Crossref.

Schultz, D. M., E. C. Gruntfest, M. H. Hayden, C. C. Benight, S. Drobot, and L. R. Barnes, 2010: Decision making by Austin, Texas, residents in hypothetical tornado scenarios. Wea. Climate Soc., 2, 249-254, Crossref.

Sherman-Morris, K., 2005: Tornadoes, television and trust-A closer look at the influence of local weathercaster during severe weather. Environ. Hazards, 6, 201-210, Crossref.

, 2010: Tornado warning dissemination and response at a university campus. Nat. Hazards, 52, 623-638, Crossref.

, K. B. Antonelli, and C. C. Williams, 2015: Measuring the effectiveness of the graphical communication of hurricane storm surge threat. Wea. Climate Soc., 7, 6982, Crossref.

Slovic, P., E. Peters, M. L. Finucane, and D. G. MacGregor, 2005: Affect, risk, and decision making. Health Psychol., 24. S35-S40, Crossref.

Tan, A. K. O., 1976: Public media use and preference for obtaining weather information. Journalism Mass Commun. Quart., 53, 694-699, Crossref.

Whitehead, J. C., 2005: Environmental risk and averting behavior: Predictive validity of jointly estimated revealed and stated behavior data. Environ. Resour. Econ., 32, 301-316, Crossref.

Wilson, K., 2008: Television weathercasters as potentially prominent science communicators. Public Underst. Sci., 17, 73-87, Crossref. 